\title{
Contributions to the Cytogenetics of Emilia Cass. I. Genome-dependent chiasma frequency and spontaneous chromosome aberrations
}

\author{
Omotoye Olorode and D. J. Olopade \\ Department of Biology, University of Ife, Ile-Ife, Nigeria
}

Received January 6, 1977

In the course of previous studies, hybrids were obtained from Emilia sonchifolia (L.) DC and Emilia coccinea (Sims) G. Don and the hybrids were phenotypically close to E. praetermissa Milne-Redhead (Olorode and Olorunfemi 1973, Olorode 1973a). It was further shown that by artificially doubling the chromosomes of Emilia sonchifolia-E. coccinea hybrids the resultant amphiploid is phenotypically and karyotypically indistinguishable from Emilia ptaetermissa-an $n=10$ natural amphiploid.

One can see that Emilia praetermissa is an amphitetraploid of hybrid origin with $E$. sonchifolia $(n=5)$ and $E$. coccinea $(n=5)$ as the diploid progenitors. This conclusion was reinforced by statistical analyses which showed that the chromosomes of $E$. coccinea are larger than those of $E$. sonchifolia and that these differences are detectable in the artificial amphiploids and in E. praetermissa-the natural amphiploid (Olorode 1973).

The first part of this paper deals with satistical validation of the observations that a) more chiasmata are formed by chromosomes of $E$. coccinea than by chromosomes of $E$. sonchifolia and b) that $E$. coccinea genome (the large bivalents) forms more chiasmata in the artificial and the natural tetraploids than $E$. sonchifolia genome (the smaller bivalents). We have also attempted to ascertain if age-an intrinsic factor-and season-an extrinsic factor exert any detectable influence on chiasma frequency.

The second observation reported in this paper concerns the occurrence of natural structural and meiotic aberrations which indicate that the genome of Emilia coccinea is quite labile in the diploid parent.

\section{Materials and methods}

For cytological observations, young flower buds were obtained from experimental or natural populations and fixed in acetic acid-alcohol $(1: 3)$ for at least 24 hours. Meiotic preparations were made by squashing anthers (from fixed materials) in propiono-orcein.

Plants for chiasma frequency data were from either experimental (E. sonchifolia, $E$. praetermissa) or natural and experimental (E. coccinea) populations. Cytological materials were obtained in the wet (rainy) season (June, July) and in the dry season (December, January). Young plants imply plants producing flowers for the 
first time-this means the first five heads were collected for chiasma analyses and the plants were labelled. Exactly 20 days after buds were so collected on $E$. sonchifolia, buds were collected again from the same plants which were then considered old plants. For E. praetermissa, artificial amphiploid and E. coccinea, the second round of bud collections were made 40 days after the first. The determination of old age was arbitrary and 40 days was used for the last three entities because they generally live longer than $E$. sonchifolia.

The dry season populations were all experimental populations because it was difficult to obtain young seedlings from natural populations. All the taxa were started under partial shape with regular watering for about a week after germination. They then ceased to get any care; in this way, a natural situation was at least partially simulated.

Chiasma frequencies were scored only in those cells where regular bivalents were formed and during early diakinesis.

For the observations on meiotic aberrations two natural populations were examined and they were designated populations $\mathrm{A}$ and $\mathrm{B}$; both of them on the campus at the University of Ife. The plant designated SS 7 was a single plant which was found to be highly pollen sterile in nature although this sterility fluctuated extremely when it was brought under garden conditions.

\section{Observations}

Chiasma frequency

Table 1 is a summary of all the data on chiasma frequency. The body of the table shows the means and standard deviations of chiasma frequency for all the

Table 1. Three-way table showing mean ${ }^{1}$ chiasmata frequency per cell (standard deviation in bracket) using genome, season and age as the factors

\begin{tabular}{llccccc} 
& \multirow{2}{*}{ Genome } & \multicolumn{2}{c}{ Old } & & \multicolumn{2}{c}{ Young } \\
\cline { 6 - 7 } \cline { 5 - 6 } & & Wet & Dry & & Wet & Dry \\
\hline $\mathrm{C}:$ & Emilia coccinea & 8.15 & 9.00 & & 7.70 & 9.05 \\
& & $(1.182)$ & $(1.076)$ & & $(1.455)$ & $(0.686)$ \\
$\mathrm{S}:$ & Emilia sonchifolia & 5.75 & 5.35 & & 5.75 & 5.40 \\
& & $(0.786)$ & $(0.587)$ & & $(0.581)$ & $(0.598)$ \\
THc: & E. coccinea genome in & & & & \\
& artificial amphiploid & 8.28 & 8.70 & & 8.40 & 8.95 \\
& & $(1.333)$ & $(1.174)$ & & $(1.392)$ & $(1.050)$ \\
THs: & E. sonchifolia genome in & & & & \\
& artificial amphiploid & 5.50 & 5.25 & & 5.30 & 5.30 \\
& & $(0.761)$ & $(0.444)$ & & $(0.470)$ & $(0.470)$ \\
Pc: & E. coccinea genome in & & & & \\
& E. praetermissa & 9.10 & 9.05 & & 8.70 & 9.00 \\
& & $(0.968)$ & $(0.823)$ & & $(1.342)$ & $(0.649)$ \\
Ps: & E. sonchifolia genome & & & & \\
& in E. praetermissa & 5.55 & 5.45 & & 5.30 & 5.25 \\
& & $(0.759)$ & $(0.605)$ & & $(1.852)$ & $(0.444)$ \\
\hline
\end{tabular}

1 Based on 20 observations. 
combinations of the three factors-genome, age, and season.

The two off-hand observations one can make on the basis of Table 1 are first, that more chiasmata are formed in E. coccinea than in E. sonchifolia; and secondly, that more chiasmata are formed by $E$. coccinea genome than $E$. sonchifolia genome in the tetraploids. It is also noteworthy that although there is no unequivocal trend, the standard deviations (and therefore the variances) appear to vary with the means. We do not consider this phenomenon sufficiently obvious to invalidate application of analysis of variance to our data, we are assuming, that is, that our variances are equal (Steel and Torrie 1960, Sokal and Rohlf 1969, Olorode 1973).

Table 2 shows that of all the main effects (factors) only intergenomic differences are significant-highly significant. There is no significant difference between the ages and between the seasons. Of the first order interactions only the one between

Table 2. Analysis of variance table on the data summarised in Table 1

\begin{tabular}{|c|c|c|c|c|}
\hline Sources of variation & $\mathrm{df}^{1}$ & SS & MS & $\mathbf{F}$ \\
\hline \multicolumn{5}{|l|}{ Main effects: } \\
\hline Age (Factor A) & 1 & 0.83 & 0.83 & $0.8298^{\mathrm{ns}}$ \\
\hline Genome (Factor B) & 5 & 1273.85 & 254.77 & $254.7191^{* * *}$ \\
\hline Season (Factor C) & 1 & 4.41 & 4.41 & 4.4091 \\
\hline \multicolumn{5}{|l|}{ First-order interactions: } \\
\hline $\mathbf{A} \times \mathbf{B}$ & 5 & 2.92 & 0.5840 & $0.5839^{\mathrm{n} s}$ \\
\hline$A \times C$ & 1 & 1.21 & 1.2100 & $1.2098^{\mathrm{ns}}$ \\
\hline $\mathrm{B} \times \mathrm{C}$ & 5 & 28.34 & 5.6680 & $5.6669^{*}$ \\
\hline \multicolumn{5}{|l|}{ Second-order interaction: } \\
\hline $\mathbf{A} \times \mathbf{B} \times \mathbf{C}$ & 5 & 438.24 & 87.6480 & $87.6305^{* * *}$ \\
\hline Error & 437 & 437.10 & 1.0002 & \\
\hline Total & 479 & 2186.90 & & \\
\hline $\begin{array}{l}1 \text { The total for df colur } \\
\text { this anova table. } \\
\text { * Probability between } \\
\text { *** Probability less that }\end{array}$ & $\begin{array}{l}f 19= \\
\%\end{array}$ & cause df & ells (see Tab) & 1) is not incl \\
\hline
\end{tabular}

'genome' and 'season' is significant-not highly significant. The third-order interaction (among the three factors) is highly significant. Figures 1-3 corroborate the intergenomic chiasma-frequency differences observed.

\section{Spontaneous chromosome aberrations}

Table 3 summarises the data on meiosis in Emilia coccinea. About 20\% of the cells observed in each of diakinesis, anaphase I and anaphase II show one kind of aberration or another.

Diakinesis aberrations include the occurrence of univalents and varying classes of multivalents such that there were cells with $3_{I I}$ and $1_{I V}, 4_{I I}$ and $2_{1}, 1_{I I}$ and $1_{V I I I}$, $1_{I I}$ and $2_{I V}$ (Olopade 1973). Figure 4 shows a pachytene cell with the typical crossconfiguration of translocation heterozygotes while Fig. 2 shows a quadrivalent which may also have resulted from translocation heterozygosity.

Anaphase I aberrations include non-disjoining bivalents (Fig. 5), non-disjunc- 


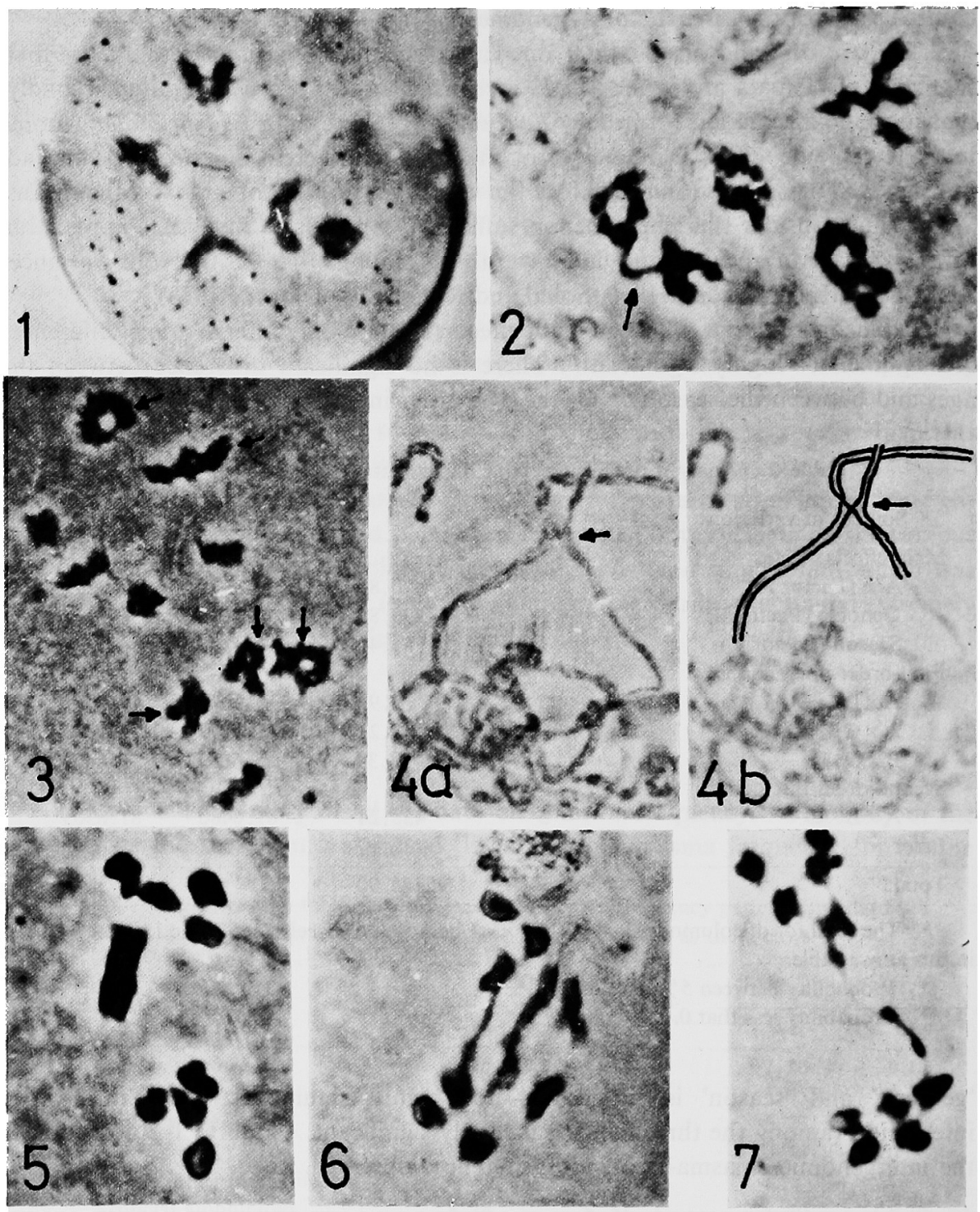

Figs. 1-7. 1, diakinesis in Emilia sonchifolia $(n=5)$; each bivalent has one chiasma. $\times 1500.2$, diakinesis in $E$. coccinea $(n=5)$; three of the bivalents have two chiasmata each, the other two have one each. The arrow points to a quadrivalent. $\times 1500.3$, diakinesis in Emilia sonchifolia-E. coccinea artificial amphiploid $(n=10)$. The large bivalents (arrows) are $E$. coccinea chromosomes, note that they form more chiasmata. The smaller bivalents are $E$. sonchifolia chromosomes with one chiasma each. $\times 1250$. $4 a$, pachytene in $E$. coccinea. Arrow shows cross-configuration indicating translocation heterozygosity. $\times 1500.4 \mathrm{~b}$, as in Fig. $4 \mathrm{a}$ with the cross configuration inked in. 5, anaphase $I$ in $E$. coccinea showing four chromosomes near pole and a non-disjoining bivalent. $\times 1250$. 6, multiple non-disjunction in anaphase I of E. coccinea. $\times 1250$. 7 , anaphase I bridge in E. coccinea with multiple regions of attenuation. $\quad \times 1250$. 
tion bridges (Figs. 6, 7) bridge-and-fragment configurations and lagging univalents (Olopade 1973). During anaphase II, bridge-and-fragment configurations and lagging chromosomes were also observed (Table 3).

Table 3. Meiotic data on natural and experimental populations of Emilla coccinea ${ }^{1}$

\begin{tabular}{|c|c|c|c|c|c|c|}
\hline & \multicolumn{2}{|c|}{ Diakinesis } & \multicolumn{2}{|c|}{ Anaphase I } & \multicolumn{2}{|c|}{ Anaphase II } \\
\hline & $\begin{array}{l}\text { No. of } \\
\text { cells } \\
\text { examined }\end{array}$ & $\begin{array}{c}\% \text { with } \\
\text { aberrations* }\end{array}$ & $\begin{array}{l}\text { No. of } \\
\text { cells } \\
\text { examined }\end{array}$ & $\begin{array}{c}\% \text { with } \\
\text { aberrations** }\end{array}$ & $\begin{array}{l}\text { No. of } \\
\text { cells } \\
\text { examined abe }\end{array}$ & $\begin{array}{l}\% \text { with } \\
\text { rrations** }\end{array}$ \\
\hline \multicolumn{7}{|l|}{ Population } \\
\hline A & 265 & 20.75 & 134 & 25.67 & 118 & 17.79 \\
\hline \multicolumn{7}{|l|}{ Population } \\
\hline B & 121 & 19.83 & 59 & 25.26 & 71 & 29.58 \\
\hline SS 7 & 458 & 28.83 & 266 & 20.30 & 234 & 27.63 \\
\hline \multicolumn{7}{|l|}{ SS $7 x$} \\
\hline Normal & 325 & 28.03 & 186 & 27.50 & 162 & 24.07 \\
\hline
\end{tabular}

Discussion

\section{Chiasma frequency}

For purposes of simplicity and since we have no contrary evidence in this genus, we have adopted the generally accepted idea that chiasmata are manifestations of recombination events. Many factors are known to affect recombination (and therefore chiasma) frequency (Swanson 1957, Swanson et al. 1967). Among those factors more thoroughly investigated are extrinsic factors such as temperature (Stern 1926, Mather 1939) and season (Oyidi 1968) or intrinsic factors such as age (Bridges 1927, Oydi 1967) and amount and position of heterochromatin on the chromosomes (Mather 1939). The data of Mather (1939) also showed that heterochromatin (an intrinsic factor) and temperature (an extrinsic factor) may interact to affect recombination in a specific way.

It is on the basis of this previous knowledge that we have included one easily ascertainable extrinsic factor (seasons) in our experimental design.

Since no significance was detectable in chiasma frequency between the ages and between the seasons, the only explanation we have to make with respect to main effects is why there are intergenomic differences. It is obvious that the frequency of chiasmata in Emilia sonchifolia is similar to the frequency in "sonchifolia" genomes of the tetraploids while the frequency of chiasmata in $E$. coccinea is similar to "coccinea" genomes in the tetraploids. It is also obvious that "coccinea" genome forms more chiasmata than "sonchifolia" genome.

There are two ways to explain the differences in chiasma frequency between "coccinea" genome and "sonchifolia" genome. One way is to attribute the differences to mechanical problems of crossing over as a function of the length of pachy- 
tene chromosome. The other way is to invoke the intervention of a qualitative structural difference between the genomes such as amount and distribution of heterochromatin.

The first explanation assumes that when autosyndetic pairing occurs during pachytene, the pachytene lengths of chromosomes in "coccinea" (C) genome are greater than those of "sonchifolia" (S) genome. On the basis of previous work (Olorode 1973) this appears to be a legitimate assumption. It has also been observed that in diploid $E$, sonchifolia- $E$. coccinea hybrids, pairing chromosomes have the same length during pachynema but not later; our original assumption of intergenomic inequality of size gets complicated! There is one way of resolving this complication if we want to accept the first hypothesis by arguing that the equality in length of pachytene chromosomes in the diploid hybrid is only apparent and that in reality one homologue has undetectable "folds" all along its length as if it had little tandem duplications!

The resolution of the first explanation leads one comfortably to the next one namely, that the two genomes have qualitative structural differences. In a previous paper (Olorode 1973) heterochromatisation was invoked to explain the difference in size between the chromosomes of $E$. coccinea and $E$. sonchifolia although Feulgen staining failed to give unequivocal answer. Quite a few workers including (quite recently) Erhendorfer (1970) have suggested that when there is conspicuous chromosome-size difference in related species, the existence of heterochromatin should be suspected in the genome showing greater size.

The first-order interaction between genome and season (although rather feeble) is fascinating. Table 1 indicates that chiasma frequency depends on genome and on the season although no consistent trend can be discerned. The second-order interaction also corroborates previous observations that many factors do interact to affect recombination frequency.

The ecological relationships of the three species of Emilia were discussed in previous studies (Olorode 1973, Olorode and Olorunfemi 1973). Phylogenetically, available evidence point to the conclusion that Emilia sonchifolia is more derived than $E$. coccinea. The more derived taxa are generally considered to be self compatible, to show a tendency towards reduction of recombination and heterozygosity and to be able to occupy more rigorous and specialised (e. g. xeric) habitats (Erhendorfer 1970). All these genetic and ecological attributes are found in E. sonchifolia while the contrary is true for $E$. coccinea.

Since $E$. sonchifolia occupies more xeric (specialised) habitats, a fairly uniform progeny is advantageous in every generation, therefore recombination and consequently chiasma frequency is minimal. On the other hand since $E$. coccinea occupies a mesic and therefore fairly optimal habitat recombination and heterozygosity can be tolerated: this explains the higher chiasma frequency. The behaviour of the genomes (with respect to chiasma frequency) at the diploid level is retained in the amphiploid. Since pairing in the amphiploid is mostly intragenomic, the advanced generations closely approach the $F_{1}$ morphologically and segregation for the characters of the diploid parents is very rare. 


\section{Chromosome aberrations during meiosis}

From meiotic studies in Emilia sonchifolia-E. coccinea hybrids it was concluded (Olorode and Olorunfemi 1973, Olorode 1973a) that evolution at diploid level in West African Emilia was accompanied by structural changes such as inversions and translocations. The observations recorded in this paper on aberrations in Emilia coccinea indicate that the evolutionary forces that created the structural differences between $E$. coccinea and $E$. sonchifolia are very much active.

The genome of $E$. coccinea therefore appears to be especially labile at the diploid level. Because $E$. coccinea is a perennial herb (as opposed to the annual or semiperennial situation in E. sonchifolia) it has a long life span to "experiment" with many structural changes which can be released into the environment and "tested" by natural selection. We think this is how E. sonchifolia evolved from its ancestor which may be E. coccinea.

One possible consequence of the occurrence of non-disjoining bivalents (Fig. 6) is that both chromosomes may pass to the same nucleus leading to the production of $n=6$ gamete and, in the subsequent generation, trisomy which may have a selective advantage (Ohno 1970). Breakage of non-disjunction bridges may also lead to the evolution of deletions and duplications in the resultant gametes; the evolutionary significance of these phenomena are all too well-known to be over-laboured.

\section{Summary}

Factorial analysis of variance was carried out on chiasma frequency in the genomes of Emilia Cass. using age, genome and season as the factors. Chiasma frequency was significantly greater in "coccinea" genomes than in "sonchifolia" genome; the other factors (age and season) showed no significance. There was a significant first-order interaction (season $\times$ genome) and a second-order interaction. The evolutionary significance of spontaneous chromosome aberrations in Emilia. coccinea (Sims) G. Don is discussed.

\section{Acknowledgement}

The assistance of Mr. Adebowale Aderinto who computed the data in Tables 1 and 2 is gratefully acknowledged.

\section{Literature Cited}

Bridges, C. B. 1927. The relation of the age of the female to crossing-over in the third chromosome of Drosophila melanogaster. Jour. Gen. Physiol. 8: 698-700.

Ehrendorfer, F. 1970. Evolutionary patterns and strategies in seed plants. Taxon 19: 185-195.

Mather, K. 1939. Crossing-over and heterochromatin in the X-chromosome in Drosophila melanogaster. Genetics 24: 413-435.

Ohno, S. 1970. Evolution by Gene Duplication. George Allen \& Unwin, London.

Olopade, D. J. 1973. Spontaneous chromosome aberrations in Emilia coccinea. Unpublished B. Sc. (Biology) dissertation, University of Ife,

Olorode, O. 1973. Identification of the genomic complements of Emilia praetermissa (Seneci- 
oneae-Compositae). Amer. Jour. Bot. 60: 55-60.

- 1973a. Meiotic studies on the diploid hybrid between "Emilia sonchifolia and E. coccinea (Compositae)". Cytologia 38: 725-729.

- and Olorunfemi, A. E. 1973. The hybrid origin of Emilia praetermissa (Senecioneae-Compositae). Ann. Bot. 37: 185-191.

Oyidi, O. 1967. Variation and variability in Orthopteran insects I. The influence of age on chiasma frequency in Zonocerus variegatus L. (Acrididae). Jour. W. Afr. Sci. Ass. 12: 131-138.

- 1968. Variation and variability in Orthopteran insects II. The correlation between chiasma frequency and terminal chiasmata in natural populations of Zonocerus variegatus $\mathrm{L}$. (Acrididae). Jour. W. Afr. Sci. Ass. 13: 53-60.

Sokal, R. R. and Rohlf, F. J. 1969. Biometry. W. H. Freeman and Co., San Franciso, 369-376.

Steel, G. D. and Torrie, J. H. 1960. Principles and Procedures of Statistics. McGraw-Hill Book Company, Inc., New York.

Stern, C. 1976. An effect of temperature and ageon crossing over in the first chromosome of Drosophila melanogaster. Proc. Nat. Acad. Sci. (U.S.A.) 12: 530-532.

Swanson, C. P. 1957. Cytology and Cytogenetics. Prentice-Hall Inc., Engelwood Cliffs, New Jersey.

—, Merz, T. and Young, W. J. 1967. Cytogenetics. Prentice-Hall Inc., Engelwood Cliffs, New Jersey. 